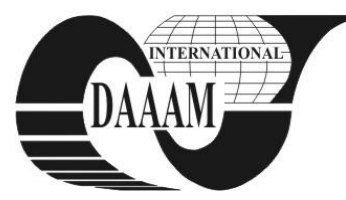

Annals of DAAAM for 2011 \& Proceedings of the 22nd International DAAAM Symposium, Volume 22, No. 1, ISSN 1726-9679 ISBN 978-3-901509-83-4, Editor B. Katalinic, Published by DAAAM International, Vienna, Austria, EU, 2011 Make Harmony between Technology and Nature, and Your Mind will Fly Free as a Bird

\title{
RECONFIGURATION IN SELF-ORGANIZING SYSTEMS
}

\author{
KUKUSHKIN, I[lya] K[onstantinovich]; KATALINIC, B[ranko]; \\ CESAREC, P[aulina] \& KETTLER, R[oman]
}

\begin{abstract}
Innovation in the field of assembling is going in many directions. One of them is a creation of a new generation of automated assembly systems, based on natural fenomena. These systems have some additional possibilities for minimization of assembling time using reconfiguration. Different possibilities of the reconfiguration are shown in this paper on the example of Bionic Assembly System.

Key words: mobile robots, assembly system, reconfiguration, assembling, rearrangement
\end{abstract}

\section{INTRODUCTION}

Migration of the products from the developed to developing countries is one of the main characteristics of modern time. One of the main reasons for this migration is labor low cost in developing countries. The products with an intensive human work are the best candidates for this migration. Typical approach of production of products in developing countries is devided in many simple steps. Developed countries are fighting against this migration in different ways, but the main are innovation and production automation.

Production of the products can be divided in following tasks: design, process planning, machining of parts, assembly. The complexity of this tasks and actual level of automation are very different. Assembly has the highest complexity of task and the lowest level of automation. This fact makes the products with intensive assembly value and time to the best migration candidates.

Innovation in the field of assembling is going in many directions. One of them is a creation of a new generation of automated assembly systems, based on natural fenomena. There is a new concept of assembly system, proposed by Katalinic (2002), based on the self-organization. The description of the system layout, functions and working scenarios and strategies are given in (Katalinic \& Kordic, 2002) and working elements in (Cesarec et. al, 2009).

Assembly stations and mobile robots are the key elements of kernel part of this system. Assembly station is able to complete one or more assembly operations on one or more different products. There can be more alternative assembly stations for the same assembly operation. Assembly stations can have fixed or movable positions in the layout. Assembly of the product is completing step by step on assembly pallet, which is carried by mobile robot, from one to the next stations.

In the comparison with the classical assembling systems this system has some additional possibilities for minimization of time for assembling one product and for assembling of one run. This can be achieved through the rearrangement of the queues for the first case and reconfiguration of layout, during the assembly for the second case.

These two possibilities are investigated and presented in this paper.

\section{MOBILE ROBOTS}

Each mobile robot gets an assembly order. It means to assemble one piece of one product. It follows step by step assembling plan of product to complete this order. Robot communicates with all assembly stations to find out, which station is able to complete next assembly operation. If there are more candidate stations, it is choosing station with the shortest completition time of operation.

It is very typical for assembly stations that there are waiting robots in the queue in front of the station as shown in (1).

$$
{ }_{P_{m}}^{O_{i}} S_{1}: \mathbf{\square}_{P_{m}}^{O_{i}} R_{1} \quad \mathbf{\square}_{P_{m}}^{O_{i}} R_{2} \ldots \mathbf{\square}_{P_{m}}^{O_{i}} R_{\text {last }}
$$

In front of the station $S$ number one for operation $i^{\text {th }}$ on $\mathrm{m}^{\text {th }}$ product are waiting robots on $\mathrm{i}^{\text {th }}$ operation in the assembling of $\mathrm{m}^{\text {th }}$ product, numbered from one till the last.

There are 3 priorities of orders $(1-$ high, 2 - normal, 3 low). Typical situation in front of the one station is described at (2).

$$
\begin{aligned}
& { }_{P_{m}, P_{n}, P_{l}, O_{k}}^{O_{1}} S_{1}: \boldsymbol{\square}_{P_{m}}^{O_{i}} R_{1}^{1} \boldsymbol{\square}_{P_{m}}^{O_{i}} R_{2}^{1} \ldots \boldsymbol{\square}_{P_{m}}^{O_{i}} R_{\text {Last }}^{1} \boldsymbol{\square}_{P_{n}}^{O_{j}} R_{1}^{2} \boldsymbol{\square}_{P_{n}}^{O_{j}} R_{2}^{2} \ldots \\
& \ldots \square_{P_{n}}^{O_{j}} R_{\text {Last }}^{2} \square_{P_{l}}^{O_{k}} R_{1}^{3} \square_{P_{l}}^{O_{k}} R_{2}^{3} \quad \ldots \square_{P_{l}}^{O_{k}} R_{\text {Last }}^{3}
\end{aligned}
$$

In station $\mathrm{S}$ it is possible to make $\mathrm{i}^{\text {th }}$ operation on $\mathrm{m}^{\text {th }}$ product, $\mathrm{j}^{\text {th }}$ operation $\mathrm{n}^{\text {th }}$ product and $\mathrm{k}^{\text {th }}$ operation on $\mathrm{l}^{\text {th }}$ product. The queues of the robots in the front of the station with the respect of priorities are formed in following sequence.

In front of the station $S$ number one for $i^{\text {th }}$ operation on $\mathrm{m}^{\text {th }}$ product, $\mathrm{j}^{\text {th }}$ operation $\mathrm{n}^{\text {th }}$ product and $\mathrm{k}^{\text {th }}$ operation on $\mathrm{l}^{\text {th }}$ product, are waiting robots on $\mathrm{i}^{\text {th }}$ operation in the assembling of $\mathrm{m}^{\text {th }}$ product, with the first priority, numbered from one till the last. Then, following robots on $\mathrm{j}^{\text {th }}$ operation in the assembling of $n^{\text {th }}$ product, with the second priority, numbered from one till the last. The last in the queue are robots on $\mathrm{k}^{\text {th }}$ operation in the assembling of $n^{\text {th }}$ product, with the the third priority numbered from one till the last.

Shortest completition time of operation is a sum of waiting time in the queue in front of the station and assembling time at the station. All the robots in the system are following the trajectory based on the criteria of the "smallest time resistance". For the operation, which can be completed on more assembly stations it is nessessary to solve the problem of changing a number of working stations.

In the case of introduce of new stations it is nessessary to rearrange the queue from the robots, waiting in front of the other station, as shown in 3 .

$$
\begin{aligned}
& { }_{P_{m}, P_{n}, P_{l}}^{O_{i}, O_{j}, O_{k}} S_{1}: \mathbf{\square}_{P_{m}}^{O_{i}} R_{1}^{1} \mathbf{\square}_{P_{m}}^{O_{i}} R_{2}^{1} \ldots \mathbf{\square}_{P_{m}}^{O_{i}} R_{\text {middle }}^{1} \ldots \mathbf{\square}_{P_{m}}^{O_{i}} R_{\text {last }}^{1} \\
& \boldsymbol{\square}_{P_{n}}^{O_{j}} R_{1}^{2} \boldsymbol{\square}_{P_{n}}^{O_{j}} R_{2}^{2} \ldots \boldsymbol{\bullet}_{P_{n}}^{O_{j}} R_{\text {middle }}^{2} \ldots \boldsymbol{\square}_{P_{n}}^{O_{j}} R_{\text {last }}^{2} \\
& { }_{P_{l}}^{O_{k}} R_{1}^{3} \square_{P_{l}}^{O_{k}} R_{2}^{3} \ldots \boldsymbol{\square}_{P_{l}}^{O_{k}} R_{\text {middle }}^{3} \ldots \boldsymbol{}_{P_{l}}^{O_{k}} R_{\text {last }}^{3} \\
& { }_{P_{m}, P_{n}, P_{l}}^{O_{i}, O_{j}, O_{k}} S_{2}: \text { Ready for the assembling }
\end{aligned}
$$

The result of rearrangement of the queues is:

$$
\begin{aligned}
& { }_{P_{m}, P_{n}, P_{l}}^{O_{i}, O_{j}, O_{k}} S_{1}: \mathbf{\square}_{P_{m}}^{O_{i}} R_{1}^{1} \mathbf{\square}_{P_{m}}^{O_{i}} R_{2}^{1} \ldots \mathbf{\square}_{P_{m}}^{O_{i}} R_{\text {middle }}^{1} \mathbf{\square}_{P_{n}}^{O_{j}} R_{1}^{2} \mathbf{\square}_{P_{n}}^{O_{j}} R_{2}^{2} \ldots \\
& \ldots \boldsymbol{\square}_{P_{n}}^{O_{j}} R_{\text {middle }}^{2} \boldsymbol{\square}_{P_{l}}^{O_{k}} R_{1}^{3} \square_{P_{l}}^{O_{k}} R_{2}^{3} \ldots \square_{P_{l}}^{O_{k}} R_{\text {middle }}^{3} \\
& { }_{P_{m}, O_{j}, O_{k}, P_{l}}^{O_{2}} S_{2}: \boldsymbol{\square}_{P_{m}}^{O_{i}} R_{\text {middle }}^{1} \ldots \boldsymbol{\square}_{P_{m}}^{O_{i}} R_{\text {last }}^{1} \boldsymbol{\square}_{P_{n}}^{O_{j}} R_{\text {middle }}^{2} \ldots
\end{aligned}
$$




$$
\ldots \boldsymbol{\square}_{P_{n}}^{O_{j}} R_{\text {last }}^{2} \boldsymbol{\square}_{P_{l}}^{O_{k}} R_{\text {middle }}^{3} \ldots \boldsymbol{\square}_{P_{l}}^{O_{k}} R_{\text {last }}^{3}
$$

In front of the station number one for $\mathrm{i}^{\text {th }}, \mathrm{j}^{\text {th }}$ and $\mathrm{k}^{\text {th }}$ operation on $\mathrm{m}^{\text {th }}, \mathrm{n}^{\text {th }}$ and $\mathrm{l}^{\text {th }}$ product are waiting robots on $\mathrm{i}^{\text {th }}$ operation in the assembling of $\mathrm{m}^{\text {th }}$ product, with the first priority, numbered from one till the middle. Then, following robots on $\mathrm{j}^{\text {th }}$ operation in the assembling of $\mathrm{n}^{\text {th }}$ product, with the second priority, numbered from one till the middle. The last in the queue are robots on $\mathrm{k}^{\text {th }}$ operation in the assembling of $\mathrm{n}^{\text {th }}$ product, with the the third priority numbered from one till the middle.

In front of the station number two for $\mathrm{i}^{\text {th }}$, $\mathrm{j}^{\text {th }}$ and $\mathrm{k}^{\text {th }}$ operation on $\mathrm{m}^{\text {th }}, \mathrm{n}^{\text {th }}$ and $\mathrm{l}^{\text {th }}$ product are waiting robots on $\mathrm{i}^{\text {th }}$ operation in the assembling of $\mathrm{m}^{\text {th }}$ product, with the first priority, numbered from middle till the end. Then, following robots on $j^{\text {th }}$ operation in the assembling of $\mathrm{n}^{\text {th }}$ product, with the second priority, numbered from middle till the end. The last in the queue are robots on $\mathrm{k}^{\text {th }}$ operation in the assembling of $\mathrm{n}^{\text {th }}$ product, with the the third priority numbered from middle till the end.

\subsection{BAS behaviour in case of assembly station failure}

It can happen that the number of assembly stations is decreasing. This can happen in case of one assembly station falure (Fig. 1.). In this case, waiting robots in the front of this station must be moved in the waiting queues in front of the active stations. This procedure we are calling rearrangement of the queues.

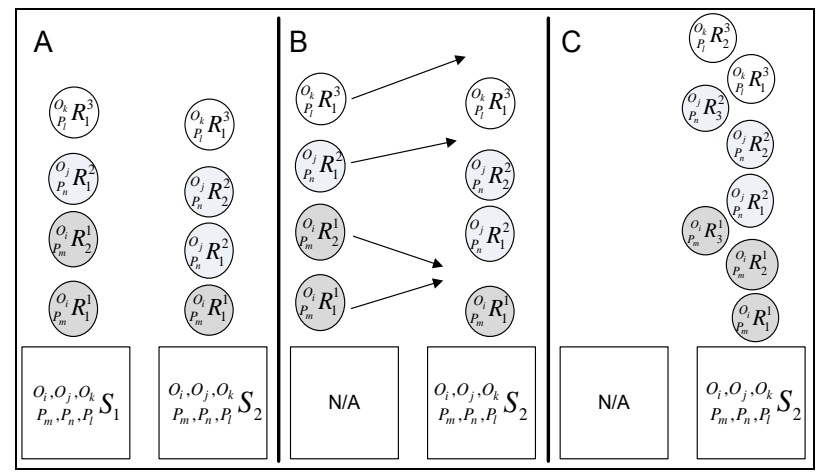

Fig. 1. Queues rearrangement in case of an assembly station falure

In front of the stations number one and two for $\mathrm{i}^{\text {th }}, \mathrm{j}^{\text {th }}$ and $\mathrm{k}^{\text {th }}$ operation on $\mathrm{m}^{\text {th }}, \mathrm{n}^{\text {th }}$ and $\mathrm{l}^{\text {th }}$ product are waiting robots on $\mathrm{i}^{\text {th }}$ operation in the assembling of $\mathrm{m}^{\text {th }}$ product, with the first priority, numbered from one till the last. Then, following robots on $\mathrm{j}^{\text {th }}$ operation in the assembling of $\mathrm{n}^{\text {th }}$ product, with the second priority, numbered from one till the last. The last in the queue are robots on $\mathrm{k}^{\text {th }}$ operation in the assembling of $\mathrm{n}^{\text {th }}$ product, with the the third priority numbered from one till the last. In case of the station number one failure mobile robots are moving to the station 2 in the following way:

Robots on $i^{\text {th }}$ operation in the assembling of $\mathrm{m}^{\text {th }}$ product, with the first priority, numbered from one till the last are coming to the end of the queue of $i^{\text {th }}$ operation in the assembling of $\mathrm{m}^{\text {th }}$ product, with the first priority, on the station two. New position at the station 2 of the first robot of the station 1 will follow the rule:

$$
N_{S_{1}}^{\stackrel{O_{i}}{P_{m}} R_{1}^{1}}=N_{S_{2}}^{{ }_{O_{i}}^{P_{m}} R_{\text {last }}^{1}}+1
$$

Then, following robots on $\mathrm{j}^{\text {th }}$ operation in the assembling of $\mathrm{n}^{\text {th }}$ product, with the second priority, numbered from one till the last are rearranged with the same rule. The last is the rearrangement in the queue of robots on $\mathrm{k}^{\text {th }}$ operation in the assembling of $n^{\text {th }}$ product, with the the third priority numbered from one till the last. Final queue is seen at Fig. 1.c.

\section{LAYOUT RECONFIGURATION IN BAS}

Structure of Bionic Assembly System allows assembling more than one type of the products in the same time. Sometimes it happens that the product types are requiring two different groups of the machines, but the robots are following the longer way to get to the needed assembly station.

In this case the system layout must be reconfigured. With the order completion and system recieves the statistic of the mobile robots movement. This data is analysed, and if 2 types of the products are identified (Fig. 2a) system initializes the process of layout reconfiguration.

Assembly stations number $1,2,3$ and 7, 8 are fulfilling product type 1 and the other are making product type 2 . Machines 8, 7 are moving closer to the 1,2,3 and 9, 10 are moved closer to 4, 5 and 6. Stations are gradually moved from 1 place to another, to create two independent layouts within one system (Fig. 2b).Assembly stations are reconfigurated to make the robot way to the machine shorter. With each assembling step stations are moved closer to each other to form a new system layout.

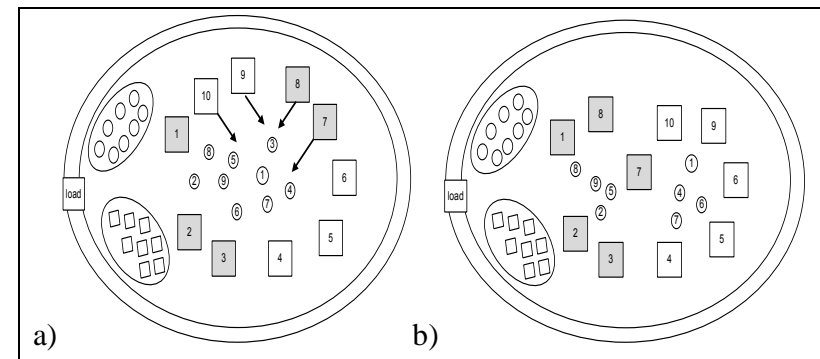

Fig. 2. Case of the layout reconfiguration in 2 independent products

\section{CONCLUSION}

A new generation of assembling systems has some additional possibilities for minimization of time for assembling one product and for assembling of one run.

This can be achieved through the rearrangement of the queues for the first case and reconfiguration of layout, during the assembly for the second case.

\section{ACKNOWLEDGEMENTS}

This paper is made with encouragement of Univ. Prof. Dr.sc. Dr.mult.h.c. Prof.h.c. Branko Katalinic and supported by the Erasmus Mundus Action 2 Programme of the European Union.

\section{REFERENCES}

Cesarec, P. (2009). Bionic Assembly System: Quieuing, Technology Matrix and Life File, Annals of DAAAM 2009 \& Proceedings of the 20th International DAAAM Symposium, pp. 21-22, vol. 20, No.1, ISSN 1726-9679, ISBN 978-3-901509-70-4, Published by DAAAM International, Vienna, Austria, EU, 2009

Katalinic, B. (2007). Collective Behaviors if an Interconnected Bionic Assembly System - Working Scenarios \& Strategies, Chapter 58 in DAAAM Internationals Scientific Book 2007, B. Katalinic (Ed.), DAAAM International, ISBN 3-901509-60-7, ISSN 1726-9687, Vienna, Austria

Katalinic, B., Kordic, V. (2002). Concept of Design and Scheduling of Self-Organizing Complex Flexible Assembly System, Proceedings of the 4th International Workshop on Emergent Synthesis - IWES 02, ISBN 961-4238-49-3, pp. 89-96, March 12-13, 2002, Kobe, Japan

Katalinic, B. \& Lazinica, A. (2005). Autonomous mobile robots in assembly applications, Chapter 25 in DAAAM International Scientific Book 2005, B. Katalinic (Ed.), Published by DAAAM International, ISBN: 3-901509-437, ISSN 1726-9687, Vienna, Austria 